\title{
EXTERNAL CHARACTERISTIC ANALYSIS AND STATOR PARAMETER OPTIMIZATION FOR A TORQUE CONVERTER
}

\author{
Maotao Zhu - Na Li* - Songlin He
}

School of Automobile and Traffic Engineering, Jiangsu University, Zhenjiang, Jiangsu, China

\begin{tabular}{l}
\hline ARTICLE INFO \\
\hline Article history: \\
Received: 21.11 .2016$. \\
Received in revised form: 20.03 .2017$. \\
Accepted: 28.03 .2017$. \\
\hline Keywords: \\
Flattened HTC \\
Stator \\
Blade \\
NURBS \\
Optimization \\
\hline DOI: http://doi.org/10.30765/er.39.3.03
\end{tabular}

\section{Introduction}

Hydraulic torque converter (HTC) plays a great role in contemporary automatic transmission systems. Its performance has a notable impact on the power, economy and comfortableness of the vehicle [1]. The typical HTC mainly contains pump, turbine and stator, transmitting power through the interaction of blades and working fluid. The performance of HTC is mostly dependent on a blade shape. Thus, it is of great significance to optimize its blade shape.

In the initial HTC design, the internal complex three dimensional (3D) viscous flow field is simplified into a one dimensional (1D) motion according to the 1D flow theory. But the 1D theory assumes that the blade is infinitely thin, ignoring the influence of the blade shape. In addition, extensive reliance of experiments and empirical formulas lowers accuracy of design, calculation and further optimization [2]. Another typical method for HTC optimization is to repeatedly prototype manufacture and bench test, which means a huge amount of workload. So simulation has become an important and effective method for the HTC performance optimization. In the literature [3], the external HTC characteristics are improved synthetically on the basis of $3 \mathrm{D}$

\begin{abstract}
:
The performance of a flattened hydraulic torque converter is optimized with orthogonal experiment and response surface method, considering parameters of its stator blade, defined with nonuniform rotational B-splines. The optimization model, with maximum of the stalling torque ratio as an objective, is determined through an external characteristic statistical analysis under the new European Driving Cycle condition. The optimization results show that the stall torque ratio is increased by $10.83 \%$, while the highest efficiency is above $84 \%$.
\end{abstract}

numerical simulation analysis. The blade shape of its pump is promoted by an orthogonal experiment about several parameters including blade angle and thickness distribution, and a synthetic optimization numerical model. Response surface method (RSM) was introduced in the literature [4] for optimization of inlet and outlet angles of a pump and turbine, as a result of which the stalling torque ratio increased while the highest efficiency declined in some degree. Overall, the optimization cases in the existing studies mainly focus on the improvement of the highest efficiency and the construction design of pump or turbine. However, according to the relevant researches, hydraulic losses from the stator account for approximately $40 \% \sim 50 \%$ of the total hydraulic loss. So optimization design of the stator blade also deserves attention. Moreover, development of a torsion vibration damping technology makes it possible for the HTC to lock automatically at a low speed. Therefore, starting and acceleration performance become a more key factor than transmission efficiency.

This paper aims to find out the optimal design parameters of the stator blade for a flattened hydraulic torque converter. Firstly, an external characteristic statistical analysis of the HTC was

\footnotetext{
* Corresponding author. Tel.: +86 15850443374;

E-mail address: onlylina@yeah.net.
} 
completed under a typical new European Driving Cycle (NEDC) condition. Then, to investigate influence on the external characteristics of each controlling parameter, an orthogonal experiment was arranged and realized with a series of 3D flow field numerical simulations. Finally, a most favorable parameter combination was found with a linear regression analysis of response surface optimization method, improving the stall torque ratio obviously and ensuring the highest efficiency at the same time.

\section{Statistical analysis}

The main characteristic indexes of a torque converter are presented as below:

$$
\begin{aligned}
& \operatorname{Tr}=\frac{M_{\text {turbine }}}{M_{\text {pump }}} \\
& \eta=\operatorname{Tr} \times i \\
& M_{\mathrm{p}} 2000=M_{\text {pump }}\left(v_{\text {pump }}=2000 \mathrm{rpm}\right)
\end{aligned}
$$

Where $i, \operatorname{Tr}$ and $\eta$ are speed ratio, torque ratio and transmission efficiency; $\mathrm{Mp} 2000$ is input torque of the pump when its speed is $2000 \mathrm{r} / \mathrm{min}$.

In engineering, $M p 2000$ is considered as an index to justify whether the engine and HTC match well or not; The stalling torque ratio $\operatorname{Tr} 0$ and the highest transmission efficiency $\eta^{*}$ are also treated as two alternative evaluation indexes to judge torque and fuel economy performance.

But now, compared to transmission system with a traditional HTC, monolithic lock-up clutch is gradually replaced by a multi-chip lock-up clutch with development of torsion vibration damping technology. As a result, the clutch engages more smoothly, avoiding sudden drop and frequent flameout due to low speed or too much vibration in the engine, and also making it possible to expand a lock-up range of locking clutch. Thus, in some current automatic transmission control strategy, clutch can be locked up once above the second gear [5]. As the analysis results of a vehicle loaded with the HTC simulated in Amsim software shown in Fig. 1, the new automatic transmission with a better torsional vibration damper has a better performance in the New European Driving Cycle (NEDC) test. The clutch in the new automatic transmission is locked up in over $73 \%$ of the total time, which is much longer than in the traditional ones.
As shown in Fig. 2, utilization of the HTC in low speed $(0 \sim 0.1)$ condition is $42 \%$ more than the one in high speed $(0.8 \sim 0.9)$ condition. Then the transmission efficiency is higher too which means more fuel-efficiency. Generally, the torque ratio under the low speed condition deserves more attention, and the key to improve the performance of the torque converter in this paper is the optimization of its torque characteristics.

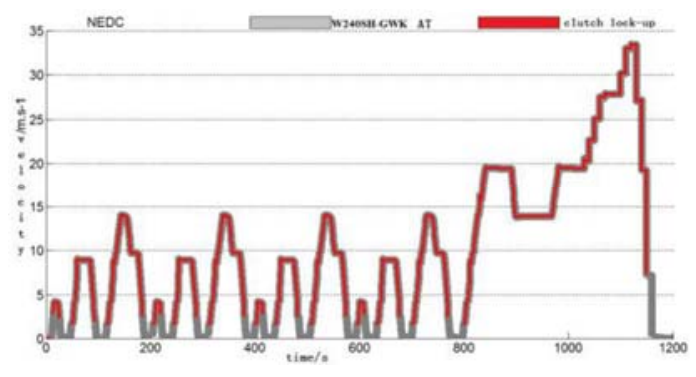

Figure 1. Torque converter locking time in the NEDC condition.

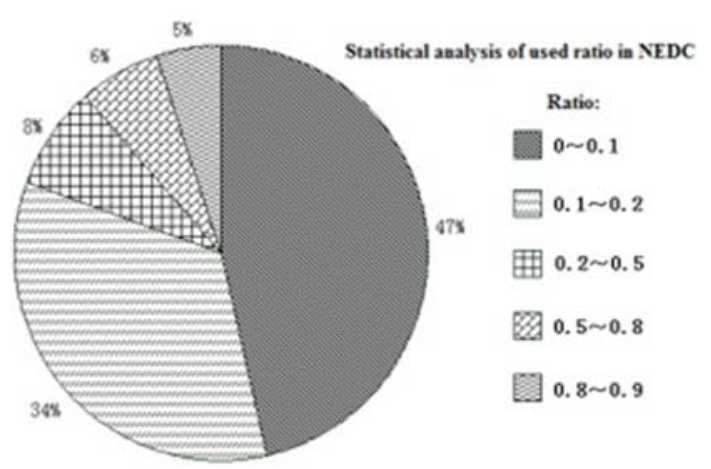

Figure 2. Statistical result of a torque converter in unlocked condition.

\section{Orthogonal experiment}

\subsection{Stator Blade Design}

The basic parameters of the W240B-SH HTC are $240 \mathrm{~mm}$ in effective diameter and $90 \mathrm{~mm}$ in the inner diameter of the circular circle. The difference between this HTC and others is the more flattened design in structure which means smaller circular flow and lower stalling torque in the pump. Thus, the efficiency and torque ratio of this HTC are relatively lower.

In order to facilitate the definition of parameters of a stator blade shape, a sample HTC was modeled with the non-uniform rotational B-splines (NURBS) and 
isometric projection method [6]. Specific definition of the stator blade parameters is shown in Fig. 3. The main five controlling parameters include thickness control coefficient $D$, camber line weight coefficient $W$, rolling angle $S$, inlet angle $\beta_{1}$ and outlet angle $\beta_{2}$. The initial values are: $D=1.2, W=1.1$, $S=-8^{\circ}, \beta_{1}=86^{\circ}, \beta_{2}=34^{\circ}$.

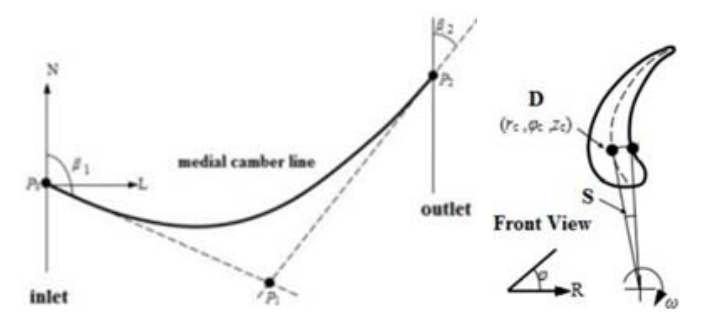

(a)

(b)

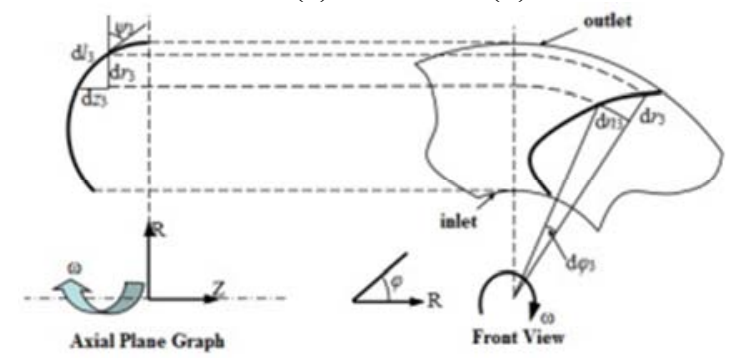

(c)

Figure 3. Stator blade shape controlling parameters.

\subsection{Numerical Simulation and Validation}

The simulation results [7] for the original model with different grid scales were validated through comparison with the bench test data in Fig. 4.

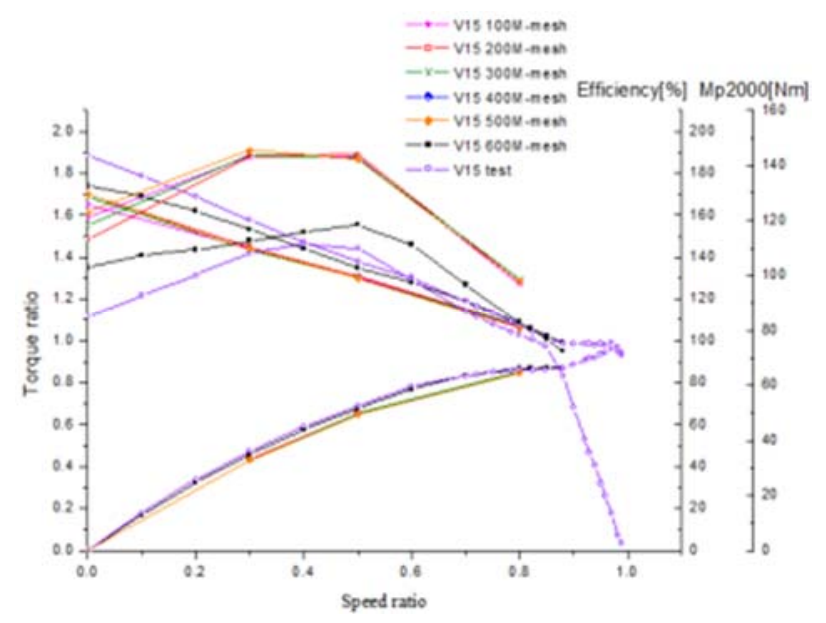

Figure 4. Comparison of test and simulation results.

As the simulation results show, the stalling torque ratio $\operatorname{Tr} 0$ is 1.884 and the highest efficiency $\eta^{*}$ is
$84.81 \%$. With the increasing grid scale, the accuracy of simulation results decreases while the computational simulation efficiency decreases. In addition, the torque ratio $\operatorname{Tr}$ and efficiency $\eta$ are in good agreement with the test results. Therefore, the simulation method can be made a further use of on the stator blade optimization.

\subsection{Experiment Factors and Plan}

To ensure the overall structure of the HTC constant, corresponding pump and turbine retain unchanged.,and considering a cyclic flow inside of the HTC and independence of design parameters, five parameters $D, S, W, \beta_{1}$ and $\beta_{2}$ were selected finally as the experimental factors for an orthogonal experiment.. The four levels of each factor are shown in Table 1.

Table 1. Levels of each experiment factor

\begin{tabular}{cccccc}
\hline \multirow{2}{*}{ Levels } & \multicolumn{5}{c}{ Factors } \\
\cline { 2 - 6 } & $D$ & $W$ & $S /{ }^{\circ}$ & $\beta_{1} /{ }^{\circ}$ & $\beta_{2}{ }^{\circ}$ \\
\hline 1 & 0.5 & 0.5 & -5.5 & 84 & 27 \\
\hline 2 & 0.8 & 1.5 & -7 & 92 & 32 \\
\hline 3 & 1.1 & 2.5 & -8.5 & 100 & 37 \\
\hline 4 & 1.4 & 3.5 & -10 & 108 & 42 \\
\hline
\end{tabular}

Then, a standard L16 $\left(4^{5}\right)$ orthogonal table was adopted, and the detailed experiment arrangements and simulation results of the 16 stator blades derived from the orthogonal table are shown in Table 2 (A, $\mathrm{B}, \mathrm{C}, \mathrm{D}$ and $\mathrm{E}$ represent coded values for $D, W, S$, $\beta_{1}, \beta_{2}$ respectively).

\subsection{Experiment Result Analysis}

In order to evaluate respective influence of these factors on the external characteristics and find out the major factors, a range analysis with the orthogonal experiment results is shown in Table 3. The sequence of the influence on the stalling torque ratio and the highest efficiency is $\mathrm{E}>\mathrm{D}>\mathrm{C}>\mathrm{A}>\mathrm{B}$ and $\mathrm{E}>\mathrm{C}>\mathrm{D}>\mathrm{A}>\mathrm{B}$ respectively.

Based on the range analysis results in Table 3, taking the levels of each experimental factor as abscissa, average simulation results of each level as ordinate, Fig. 5 is drawn to analyze influence trend of each experimental factor on the evaluation indexes. Combined with the range analysis results, the optimal level for $\eta^{*}$ is E1C4D3A2B4 while the optimal level for $\operatorname{Tr} 0$ is E1D4C4A2B1. 
Table 2. Orthogonal experiment results

\begin{tabular}{cccccccc}
\hline No. & $\mathrm{A}$ & $\mathrm{B}$ & $\mathrm{C}$ & $\mathrm{D}$ & $\mathrm{E}$ & $\operatorname{Tr} 0$ & $\eta^{* / \%} \%$ \\
\hline 1 & 1 & 1 & 1 & 1 & 1 & 1.99 & 83.9 \\
\hline 2 & 1 & 2 & 2 & 2 & 2 & 1.98 & 84.2 \\
\hline 3 & 1 & 3 & 3 & 3 & 3 & 1.91 & 84.2 \\
\hline 4 & 1 & 4 & 4 & 4 & 4 & 1.89 & 84.1 \\
\hline 5 & 2 & 1 & 2 & 3 & 4 & 1.99 & 83.7 \\
\hline 6 & 2 & 2 & 1 & 4 & 3 & 1.99 & 83.9 \\
\hline 7 & 2 & 3 & 4 & 1 & 2 & 1.96 & 84.7 \\
\hline 8 & 2 & 4 & 3 & 2 & 1 & 2.10 & 85.4 \\
\hline 9 & 3 & 1 & 3 & 4 & 2 & 2.04 & 84.3 \\
\hline 10 & 3 & 2 & 4 & 3 & 1 & 2.12 & 85.0 \\
\hline 11 & 3 & 3 & 1 & 2 & 4 & 1.89 & 84.0 \\
\hline 12 & 3 & 4 & 2 & 1 & 3 & 1.83 & 84.3 \\
\hline 13 & 4 & 1 & 4 & 2 & 3 & 2.01 & 83.8 \\
\hline 14 & 4 & 2 & 3 & 1 & 4 & 1.90 & 83.7 \\
\hline 15 & 4 & 3 & 2 & 4 & 1 & 2.11 & 85.1 \\
\hline 16 & 4 & 4 & 1 & 3 & 2 & 1.92 & 85.0 \\
\hline
\end{tabular}

Table 3. Range analysis

\begin{tabular}{cccccc}
\hline \multirow{2}{*}{$\mathrm{F}$} & \multicolumn{5}{c}{$\operatorname{Tr} 0$} \\
\cline { 2 - 6 } & $D$ & $W$ & $S /{ }^{\circ}$ & $\beta_{1} /{ }^{\circ}$ & $\beta_{2} /^{\circ}$ \\
\hline$k_{1}$ & 1.95 & 1.95 & 2.01 & 1.92 & 2.09 \\
\hline$k_{2}$ & 2.01 & 1.98 & 2.00 & 1.99 & 1.98 \\
\hline$k_{3}$ & 1.97 & 1.99 & 1.97 & 1.99 & 1.94 \\
\hline$k_{4}$ & 1.98 & 2.00 & 1.94 & 2.01 & 1.92 \\
\hline $\mathrm{R} / 10^{-3}$ & 64.9 & 44.9 & 72.6 & 85.4 & 166.0 \\
\hline \multirow{2}{*}{$\mathrm{F}$} & \multicolumn{5}{c}{$\eta^{* / \%} \%$} \\
\cline { 2 - 6 } & $D$ & $W$ & & & \\
\hline$k_{1}$ & 0.84 & 0.84 & 0.84 & 0.84 & $\beta_{1} /{ }^{\circ}$ \\
\hline$k_{2}$ & 0.84 & 0.84 & 0.84 & 0.84 & 0.85 \\
\hline$k_{3}$ & 0.84 & 0.84 & 0.85 & 0.85 & 0.84 \\
\hline$k_{4}$ & 0.84 & 0.84 & 0.85 & 0.84 & 0.84 \\
\hline $\mathrm{R} / 10^{-3}$ & 3.1 & 2.3 & 7.3 & 3.3 & 9.7 \\
\hline & & & &
\end{tabular}

\section{Optimization with RSM}

\subsection{Response Surface Theory}

With adequate experiment data obtained from the reasonable experiment design methods, multiple linear regression equations are applied to fit functional relationship between factors and response values. Then these regression equations are solved to get the optimal solution to the multi-variable problem [8].

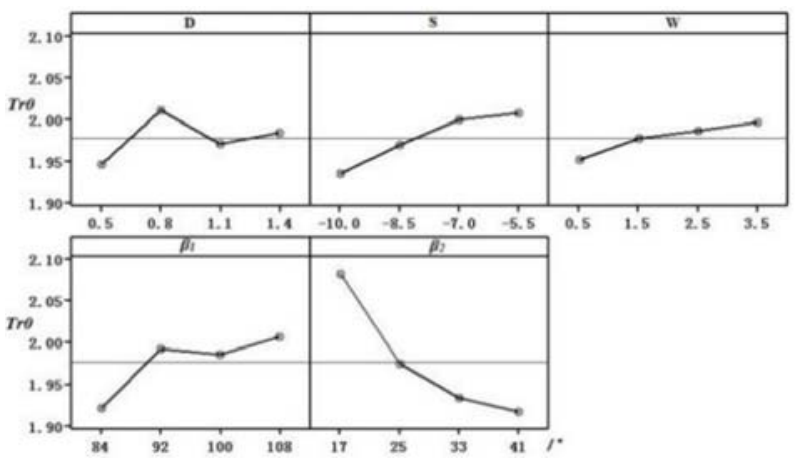

(a)

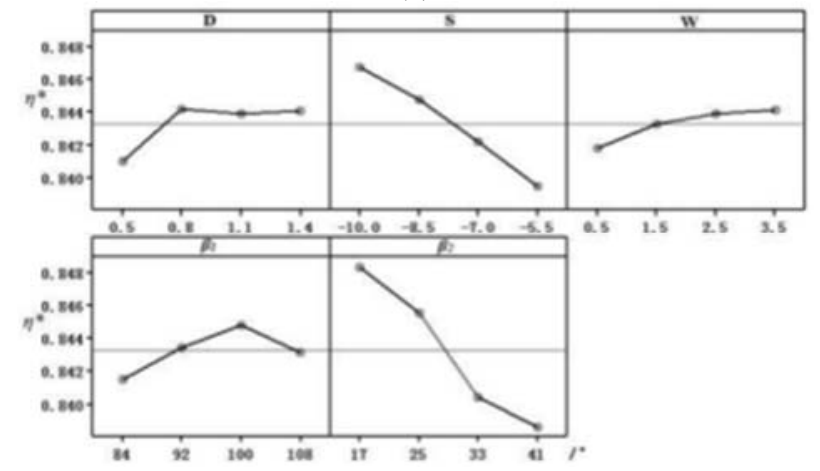

(b)

Figure 5. Influence trend on $\operatorname{Tr} 0$ and $\eta^{*}$ of each factor.

Polynomial response surface is a most widely used approximate fitting models since its mathematical expressions are more simple and easy to solve. So quadratic polynomial response surface is extensively applied in engineering, and its basic form is as follows:

$$
y_{\mathrm{m}}=\beta_{0}+\sum_{i=1}^{n} \beta_{1}^{1} x_{\mathrm{i}}+\sum_{i=1}^{n-1} \sum_{j=i+1}^{n} \beta_{\mathrm{ij}}^{2} x_{\mathrm{i}} x_{\mathrm{j}}+\sum_{i=1}^{n} \beta_{\mathrm{jj}}^{2} x_{\mathrm{i}}^{2}+\varepsilon_{\mathrm{i}}
$$

Where, $m=1$ or $2, y_{1}$ and $y_{2}$ are $\operatorname{Tr} 0$ and $\eta^{*}, \beta_{0}, \beta_{\mathrm{i}}{ }^{1}$, $\beta_{\mathrm{jj}}{ }^{2}, \beta_{\mathrm{ij}}{ }^{2}$ are respectively constant term, linear term coefficient, quadratic effect coefficient of independent parameter, and interactive effect coefficient between any two variables, $\varepsilon$ is fitting error of these equations.

\subsection{The Box-Behnken experiment design}

While sampling for a large-scale space involving considerable design variables in engineering, the Box-Behnken design (BBD) method is usually applied, a three-level design method to arrange multi-variable experiment. All design points are located in the design center and focused on the 
edges of the cube equidistant from the center. As shown in Table 4, zero experiments at the center point of the BB sample cube were repeated three times to reckon the experimental errors.

Table 4. BB design arrangements and results

\begin{tabular}{cccccc}
\hline No. & $S /{ }^{\circ}$ & $\beta_{1} /{ }^{\circ}$ & $\beta_{2} /{ }^{\circ}$ & $\operatorname{Tr} 0$ & $\eta^{* / \%}$ \\
\hline 1 & -5.5 & 70 & 29 & 2.01 & 83.5 \\
\hline 2 & -9.5 & 70 & 29 & 1.93 & 84.9 \\
\hline 3 & -5.5 & 110 & 29 & 2.02 & 84.4 \\
\hline 4 & -9.5 & 110 & 29 & 1.92 & 85.4 \\
\hline 5 & -5.5 & 90 & 17 & 2.08 & 84.4 \\
\hline 6 & -9.5 & 90 & 17 & 2.09 & 85.7 \\
\hline 7 & -5.5 & 90 & 41 & 1.96 & 83.3 \\
\hline 8 & -9.5 & 90 & 41 & 1.86 & 83.6 \\
\hline 9 & -7.5 & 70 & 17 & 2.04 & 84.8 \\
\hline 10 & -7.5 & 110 & 17 & 2.11 & 85.1 \\
\hline 11 & -7.5 & 70 & 41 & 1.90 & 83.3 \\
\hline 12 & -7.5 & 110 & 41 & 1.92 & 83.5 \\
\hline 13 & -7.5 & 90 & 29 & 1.97 & 84.8 \\
\hline 14 & -7.5 & 90 & 29 & 1.97 & 84.8 \\
\hline 15 & -7.5 & 90 & 29 & 1.97 & 84.9 \\
\hline & & & & &
\end{tabular}

Table 5. Coefficients of regressive equations (Coded Levels)

\begin{tabular}{|c|c|c|c|c|c|c|c|c|c|c|}
\hline Index & $\beta_{0}$ & $\beta_{1}{ }^{1}$ & $\beta_{2}{ }^{1}$ & $\beta_{3}{ }^{1}$ & $\beta_{12}{ }^{2}$ & $\beta_{13}{ }^{2}$ & $\beta_{23}{ }^{2}$ & $\beta_{11}{ }^{2}$ & $\beta_{22}{ }^{2}$ & $\beta_{33}{ }^{2}$ \\
\hline $\operatorname{Tr} 0$ & 1.97 & -3.22 & 1.05 & -8.58 & -0.83 & -2.70 & -1.40 & 0.05 & -0.06 & 2.65 \\
\hline$\eta^{*} / \%$ & 84.83 & 24.32 & 3.40 & -27.26 & -6.53 & -26.94 & -48.04 & -9.92 & -16.71 & -97.51 \\
\hline
\end{tabular}

\subsection{Optimization Numerical Model}

Based on the above statistical analysis results of the external characteristics for the HTC and ANOVA results, the optimization numerical model is finally built, shown in Equation (3). In this optimization model, maximization of the stalling torque ratio $\operatorname{Tr} 0$ is set as an optimization objective. The highest efficiency $\eta^{*}$ is treated as a constraint.

Design variables: $\mathrm{t} 1 \sim \mathrm{t} 3$

$$
\begin{array}{lc}
\operatorname{Max} & \operatorname{Tr} 0 \\
\text { s.t. } & \eta^{*} \geq 84 \% \\
t_{i \text { min }} \leq t_{\mathrm{i}} \leq t_{i \text { max }}(i=1,2,3)
\end{array}
$$

Where, $\operatorname{Tr} 0$ and $\eta^{*}$ are the stalling torque ratio and

\section{Multiple Linear Regression and ANOVA}

Two regression equations are obtained with $\operatorname{Tr} 0$ and $\eta^{*}$ as response values, and each coefficient in Equation (2) for different output variables is shown in Table 5.

Where, $\mathrm{F}$ is a level value of F test, Seq SS is a sum of squares of deviations, and $\operatorname{Pr}(\mathrm{P}$ value, Probability) is a decline index of result credibility; * represents generally significant when $\mathrm{P}<0.05$, and ** means extremely significant when $\mathrm{P}<0.01$;

From the analysis of variance (ANOVA) in Table 6 , as the equation is significant when $P<0.05, t_{1}, t_{3}, t_{1} t_{3}$ and $t_{3} t_{3}$ in Table 6 . is of significant influence; namely both linear terms and quadratic terms in the equation have significant influences on the response values. Moreover, the sum of squares of deviations is also tiny enough which verifies that every experiment factor selected in this paper obviously influences the external performance of the HTC, and analyses of these experiment factors are fully reasonable and effective. To conclude, the regression equations are good enough to fit experiment data, and can describe actual relationship between experiment factors and response values effectively. Therefore, they can be applied further to obtain the optimal design of the stator blade parameters. the highest efficiency; three design variables $t_{1}, t_{2}$, and $t_{3}$ are stator blade rolling angle $S$, inlet angle $\beta_{1}$, and outlet angle $\beta_{2}$ respectively; $t_{\text {imin }}$ and $t_{\text {imax }}$ are the lower and the upper limit for each design variable.

\subsection{RSM Optimization and Comparison}

The total pressure contour of the stator middle exhibition surface is depicted in Fig. 6. It shows that the flow separation phenomenon on boundary layers still exists near the optimized stator suction surface on the right, but the pressure distribution is more uniformed. In case of almost immutable impact angle with the changing turbine outlet angle, the flow is well-developed along the blade curvature and flow impact is also expanded from the front of the blade to the entire suction side, making full use 
of the optimized blade. Then, flow velocity of corresponding inlet of pump and outlet of turbine is more stable, reducing the probability of flow separation and quadratic reflux. Thus, a flow loss decreases and the highest efficiency improves.

Table 6. Results of regression analysis of $\operatorname{Tr} 0$

\begin{tabular}{cccccc}
\hline SRC & DOF & Seq SS & $\mathrm{F}$ & $\operatorname{Pr}>\mathrm{F}$ & $\begin{array}{c}\text { Signifi } \\
\text { cance }\end{array}$ \\
\hline $\mathrm{t}_{1}$ & 1 & 0.008 & 25.54 & 0.005 & $* *$ \\
\hline $\mathrm{t}_{2}$ & 1 & 0.010 & 2.71 & 0.161 & \\
\hline $\mathrm{t}_{3}$ & 1 & 0.059 & 181.6 & 0.001 & $* *$ \\
\hline $\mathrm{t}_{1} \mathrm{t}_{2}$ & 1 & 0.001 & 0.85 & 0.398 & \\
\hline $\mathrm{t}_{1} \mathrm{t}_{3}$ & 1 & 0.003 & 9.01 & 0.031 & $*$ \\
\hline $\mathrm{t}_{2} \mathrm{t}_{3}$ & 1 & 0.001 & 2.43 & 0.183 & \\
\hline $\mathrm{t}_{1} \mathrm{t}_{1}$ & 1 & $7.1 \mathrm{E}-06$ & 0.012 & 0.963 & \\
\hline $\mathrm{t}_{2} \mathrm{t}_{2}$ & 1 & $2.6 \mathrm{E}-08$ & $1 \mathrm{E}-04$ & 0.952 & \\
\hline $\mathrm{t}_{3} \mathrm{t}_{3}$ & 1 & 0.003 & 7.98 & 0.037 & $*$ \\
\hline $\mathrm{MDL}$ & 9 & 0.075 & 22.60 & & \\
\hline Error & 5 & 0.002 & & & \\
\hline Sum & 14 & 0.076 & & & \\
\hline
\end{tabular}

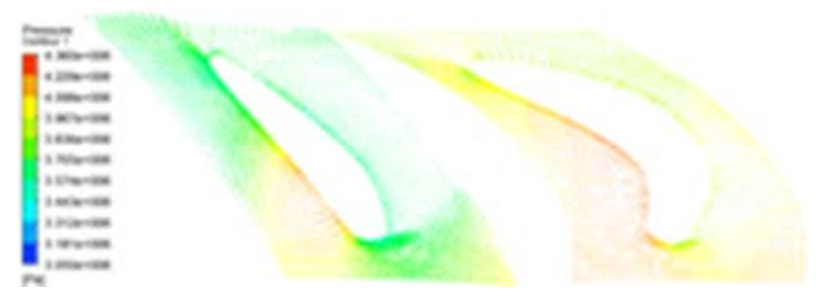

Figure 6. Original and optimized blade pressure at the stalling condition.

Table 7. Model optimization results

\begin{tabular}{cccccc}
\hline Model & $S /{ }^{\circ}$ & $\beta_{1} /{ }^{\circ}$ & $\beta_{2} /{ }^{\circ}$ & $\operatorname{Tr} 0$ & $\eta^{*} / \%$ \\
\hline Original & -8 & 86 & 34 & 1.88 & 83.8 \\
\hline Optimized & -5.74 & 92.48 & 17 & 2.09 & 84.0 \\
\hline CFD & -5.74 & 92.48 & 17 & 2.10 & 84.1 \\
\hline
\end{tabular}

In Table 7, the RSM calculation results match well with the CFD simulation results for the optimized model. The results indicate that response surface method has high precision and is suitable for model optimization for a stator blade of torque converter. In the optimized stator blade model, the rolling angle $S$ and the outlet angle $\beta_{2}$ decreases, while the inlet angle $\beta_{1}$ increases.

As shown in Fig. 7, overall performance of the HTC has obviously improved. The transmission efficiency increased distinctly under medium and low speed ratio condition; The flow loss is controlled effectively although the highest efficiency rises only by $0.2 \%$ under the high speed ratio condition. In addition, the stalling torque ratio increases by $10.83 \%$, which means a great enhance in the climbing performance, and starting and acceleration performance at a low speed.

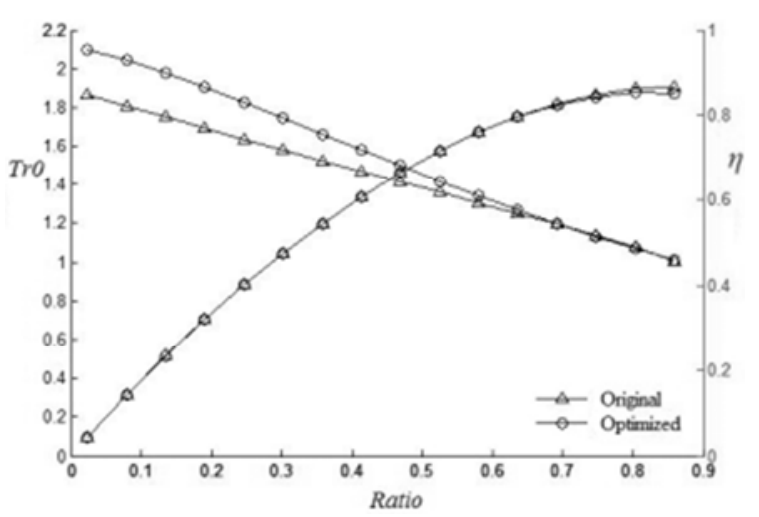

Figure 7. Comparison between the optimized and original models.

\section{Conclusion}

Performance of the flattened hydraulic torque converter has obviously been optimized with the combination of the orthogonal experiment and RSM. On the basis that $\eta^{*}$ is more than $84 \%, \operatorname{Tr} 0$ is increased by $10.83 \%$. This optimization method is feasible and can provide a basis for the future parameter analysis and optimization of torque converters.

\section{References}

[1] Wang, H., Wu, G., J, H.: Main flow features analysis on stator of super flat automotive torque converter, Journal of Jiangsu University: Natural Science Edition, 30 (2009), 5, 463-466.

[2] Zhu, J.: Design and Calculation of Hydraulic Torque Converter, National Defence Industry Press, Beijing, 1991.

[3] Han, K., Wu, G., Ji, H.: Performance optimization analysis of the effects of pump cascade key parameters on torque converter based on orthogonal design, Automotive Engineering, 32 (2010), 6, 465, 497-500.

[4] Ge, A., Tian, H., Wang, J.: Amending redesign 
of torque converter based on three dimensional flow analysis, Journal of Jiangsu University: Natural Science Edition, 26 (2005), 3, 206-208.

[5] Su, D., Qin, D.: Study on integrated control strategy for a car with a hydro-mechanical continuously variable transmission system, Chinese Journal of Mechanical Engineering, 39 (2003), 2, 102-104.

[6] Ma, W.: Hydraulic Transmission Theory and Design, Chemical Industry Press, Beijing, 2004.

[7] Zoran, C., Emil, M., Zdenko, N., Sanjin, F.: Numerical analysis of aerodynamic characteristics of a bumped leading edge turbine blade, Engineering Review, 34 (2014), 2, 93-101.
[8] Ma, D., Chu, L., Zhang, S.: Aerodynamic design and optimization for joined wing based on response surface methodology, Acta Aerodynamic Sinica, 28 (2010), 1, 113-118.

[9] Lei, Y., Ge, A., Tian, H.: Amending redesign of torque converter based on three dimensional flow analysis, Chinese Journal of Mechanical Engineering, 42 (2006), 2, 125-128.

[10] Tiankou, X.: Experimental Design Method (I), Machinery Industry Press, Beijing, 1987.

[11] Kraus S. O., Flack R. D., Habsieger A.: Periodic Velocity Measurements in a Wide and Large Radius Ratio Automotive Torque Converter at the Pump/Turbine Interface, Journal of Fluids Engineering, 127 (2005), 308-316. 